
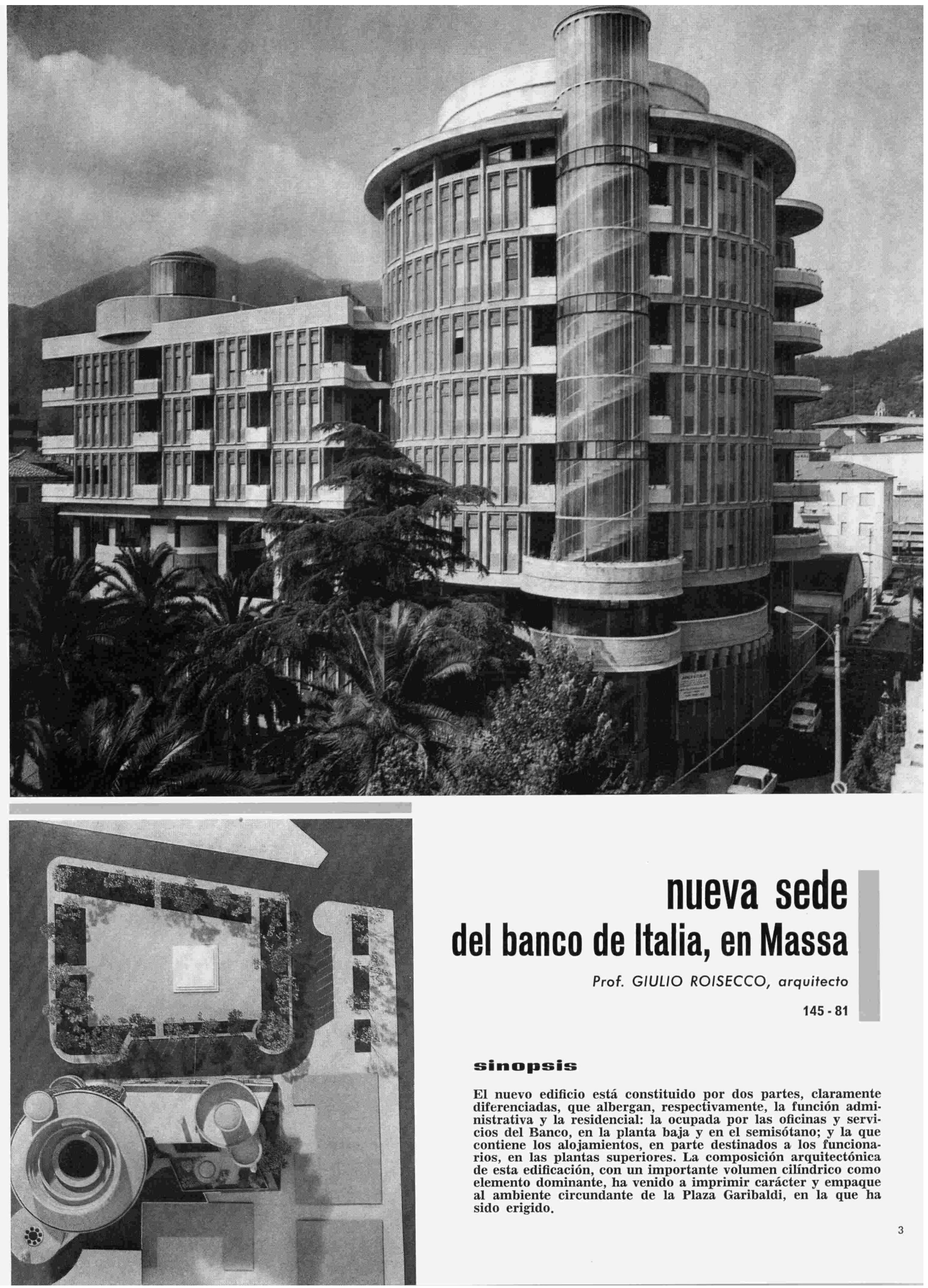

\title{
nueva sede del banco de Italia, en Massa
}

\author{
Prof. GIULIO ROISECCO, arquitecto
}

$145-81$

\section{simopsis}

El nuevo edificio está constituido por dos partes, claramente diferenciadas, que albergan, respectivamente, la función administrativa y la residencial: la ocupada por las oficinas y servicios del Banco, en la planta baja y en el semisótano; y la que contiene los alojamientos, en parte destinados a los funcionarios, en las plantas superiores. La composición arquitectónica de esta edificación con un importante volumen cilíndrico como de esta edificacion, con un importante volumen cilíndrico como al ambiente circundante de la Plaza Garibaldi, en la que ha sido erigido. 

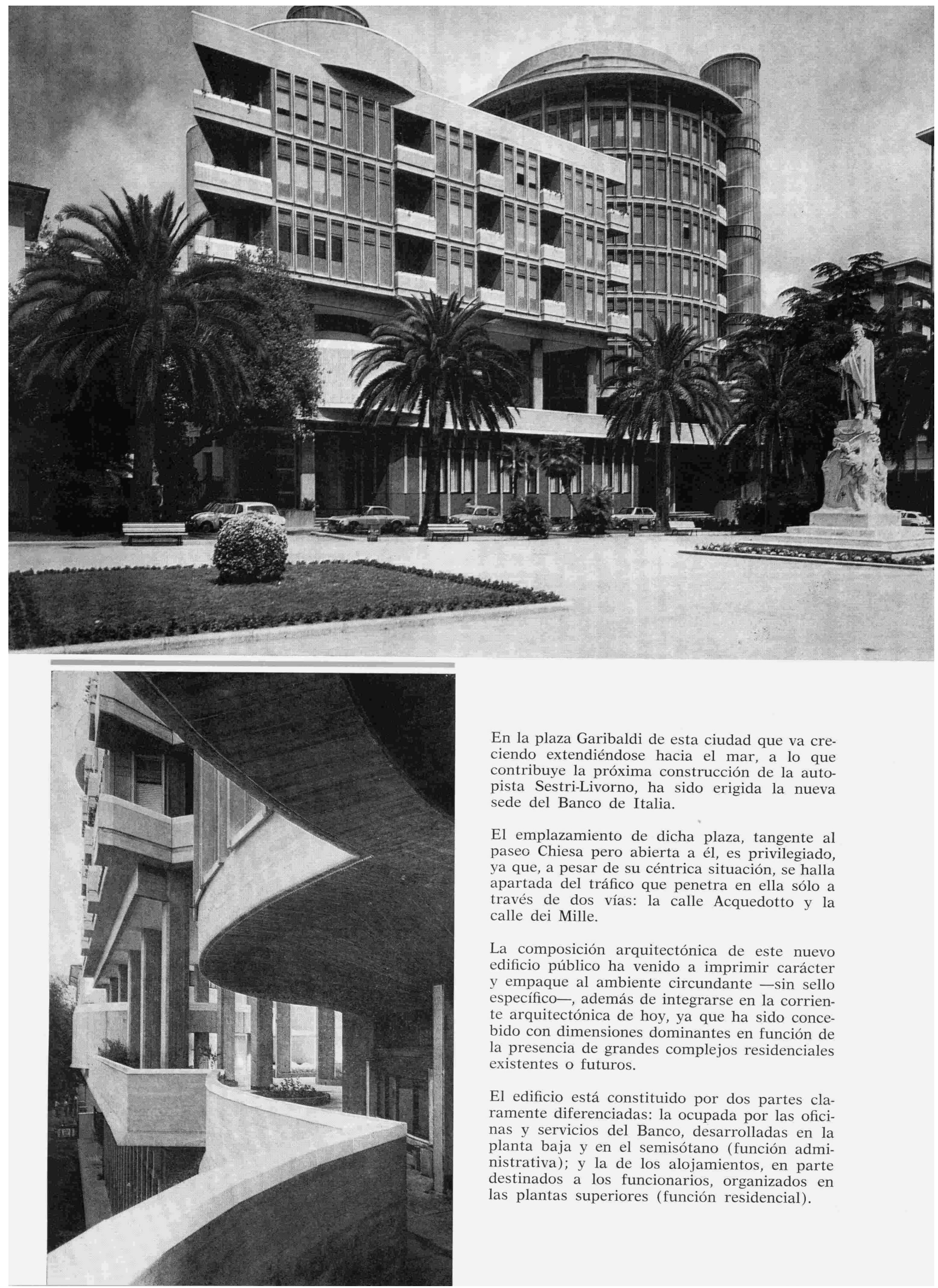

(c) Consejo Superior de Investigaciones Científicas Licencia Creative Commons 3.0 España (by-nc)

En la plaza Garibaldi de esta ciudad que va creciendo extendiéndose hacia el mar, a lo que contribuye la próxima construcción de la autopista Sestri-Livorno, ha sido erigida la nueva sede del Banco de Italia.

El emplazamiento de dicha plaza, tangente al paseo Chiesa pero abierta a él, es privilegiado, ya que, a pesar de su céntrica situación, se halla apartada del tráfico que penetra en ella sólo a través de dos vías: la calle Acquedotto y la calle dei Mille.

La composición arquitectónica de este nuevo edificio público ha venido a imprimir carácter y empaque al ambiente circundante - sin sello específico-, además de integrarse en la corriente arquitectónica de hoy, ya que ha sido concebido con dimensiones dominantes en función de la presencia de grandes complejos residenciales existentes o futuros.

El edificio está constituido por dos partes claramente diferenciadas: la ocupada por las oficinas y servicios del Banco, desarrolladas en la planta baja y en el semisótano (función administrativa); y la de los alojamientos, en parte destinados a los funcionarios, organizados en las plantas superiores (función residencial). 


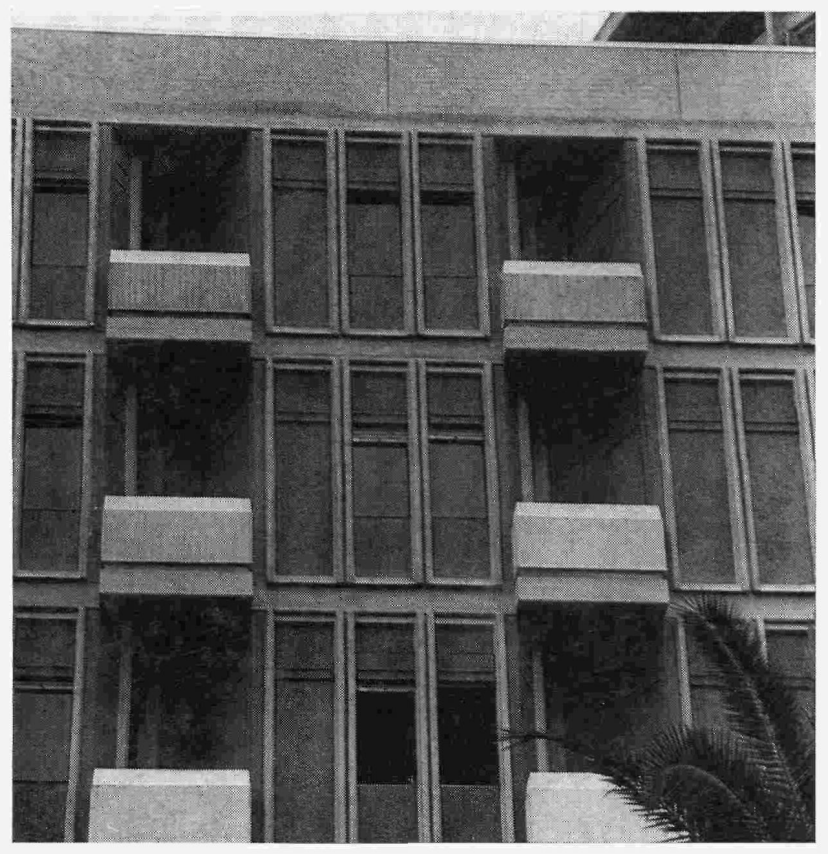

Ello ha trascendido y quedado plasmado, asimismo, en una separación horizontal de las dos zonas físicamente distintas mediante un jardín colgante, con una zona en la que puedan descansar los mayores y jugar al aire libre los niños.
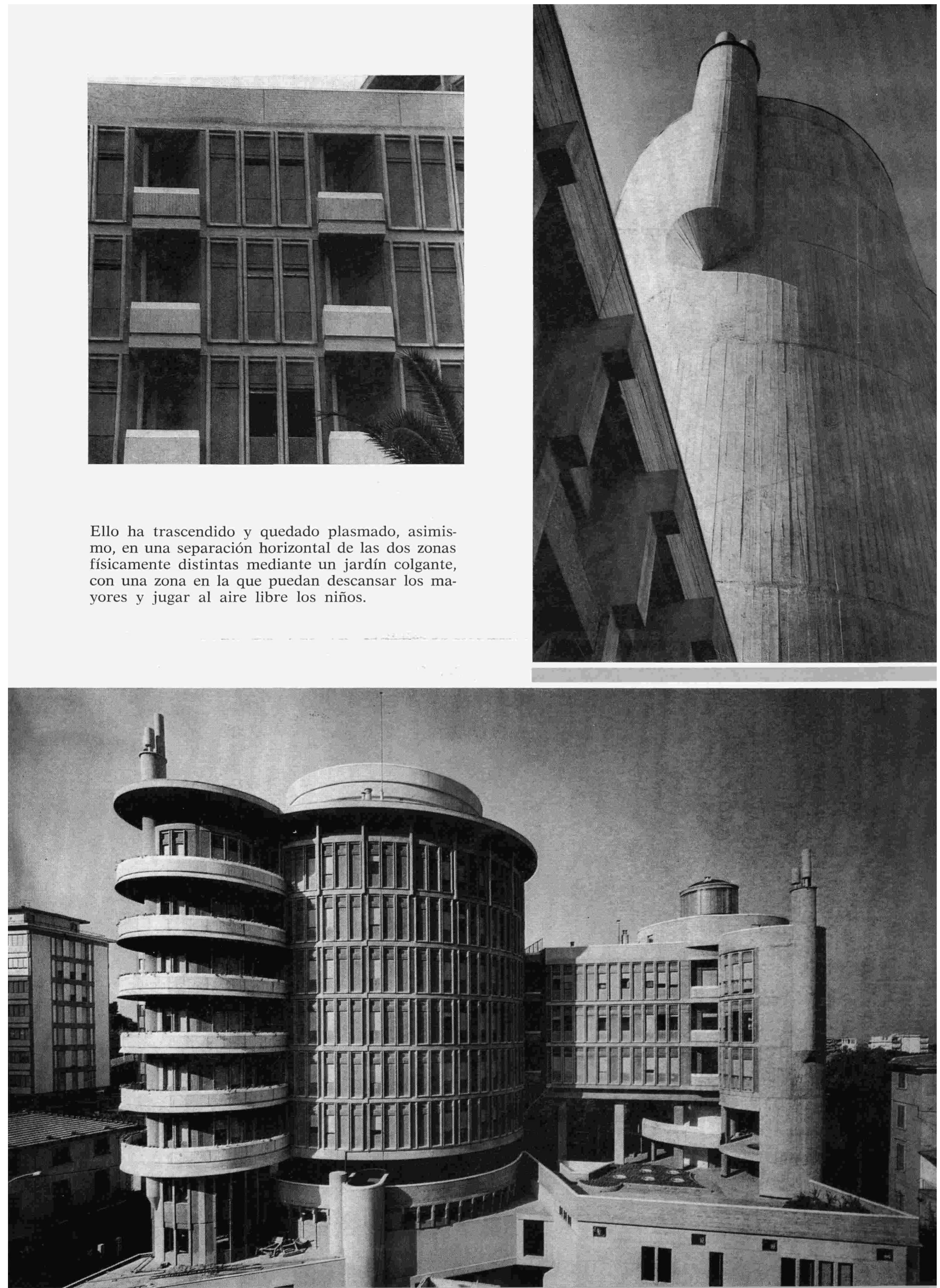


\section{planta baja}
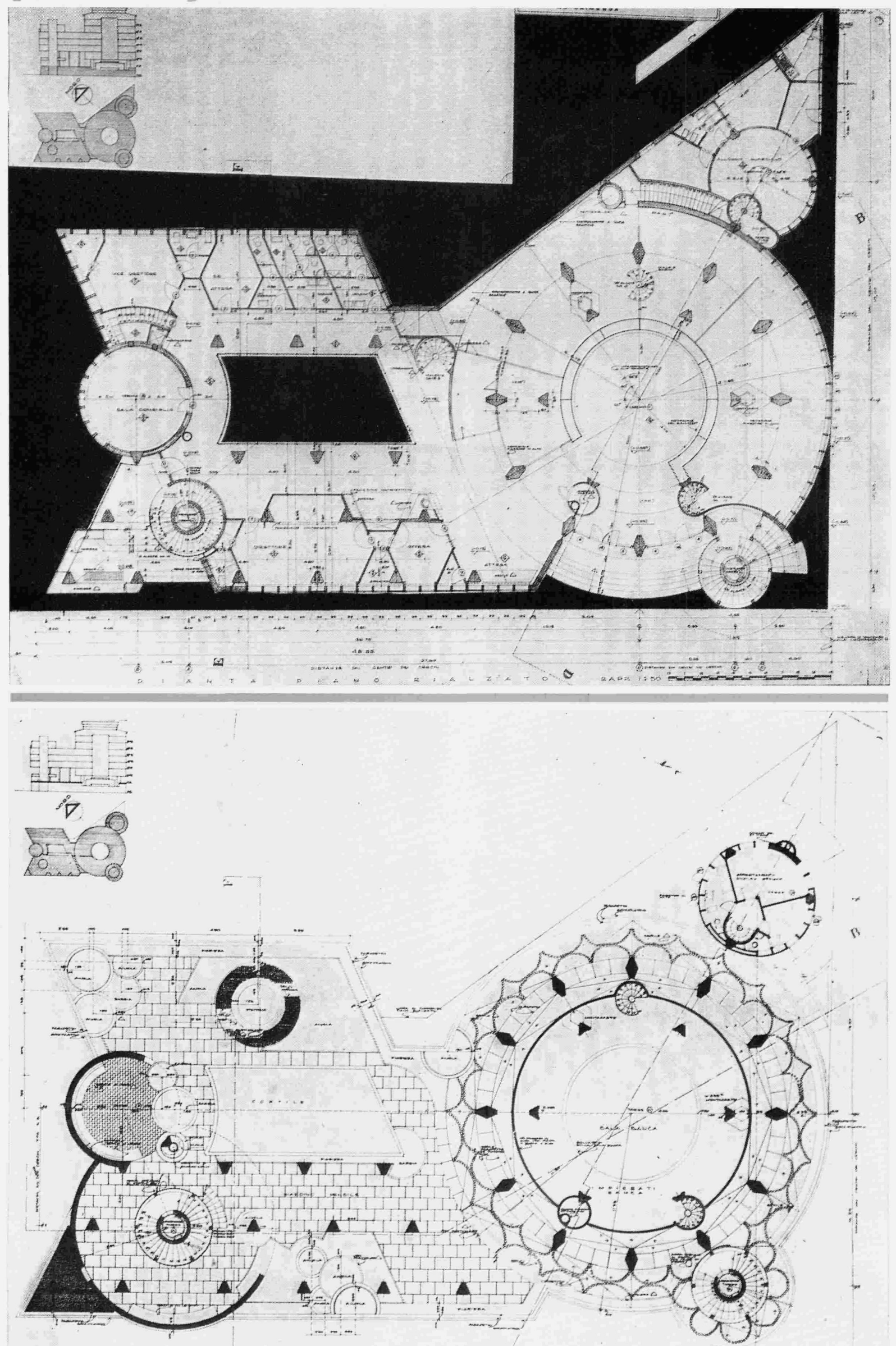

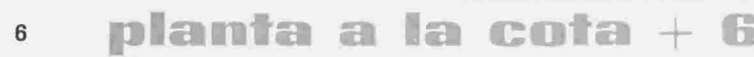



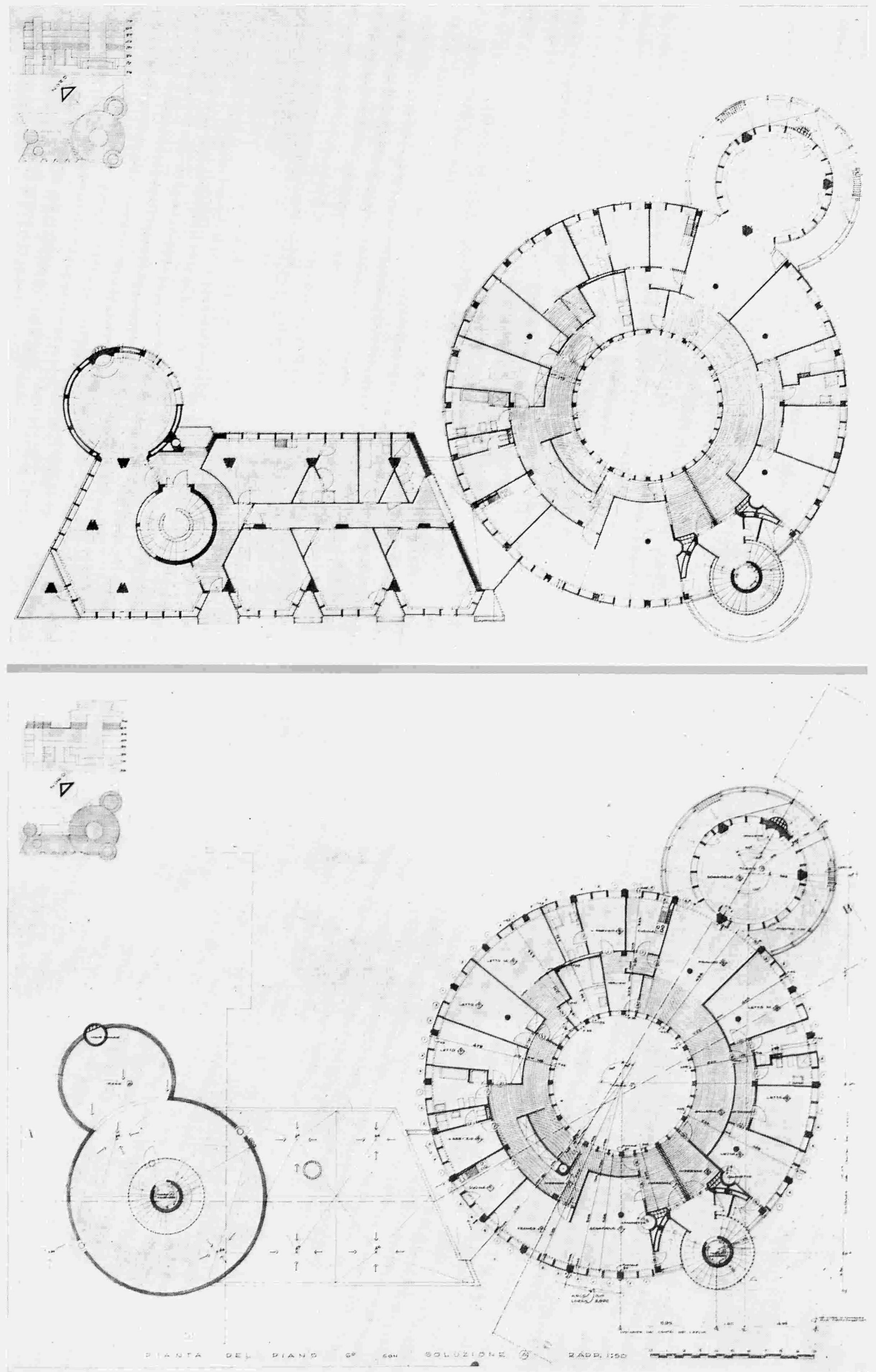


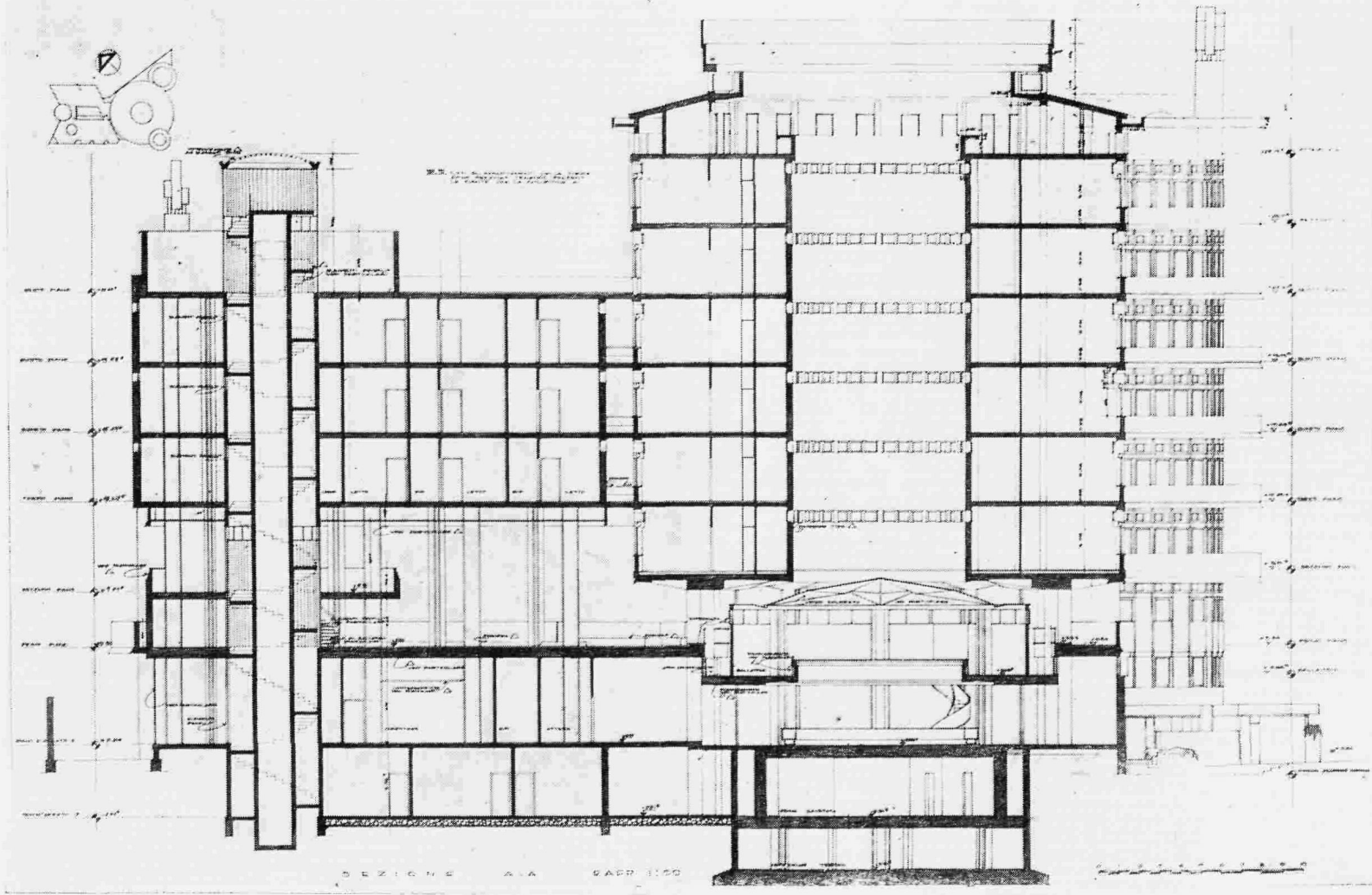

sección $A-B$

El importante volumen cilíndrico en el que se han situado la mayoría de los alojamientos, no sólo tiene como base la zona de forma circular de la sala de operaciones (indudablemente la mejor concebida desde el punto de vista funcional), sino que, en virtud de su propia "forma", ha hecho posible el que únicamente una generatriz vertical del volumen interior venga a encontrarse en la situación más desfavorable con respecto a los edificios de viviendas construidos al otro lado de la calle dei Mille.

En planta, sólo un punto del círculo (el de tangencia) se encuentra, respecto a los edificios de enfrente, a la distancia mínima representada por la anchura de la calle; todos los demás se separan con rapidez, superando holgadamente la dimensión de la citada calle.

Los alojamientos están organizados sobre el jardín colgante en tres plantas, unidas el cilindro-torre por una terraza en cada altura; el jardín colgante está dotado de instalaciones y elementos especiales destinados - como se ha dicho ya- al juego de niños y al reposo de personas mayores.
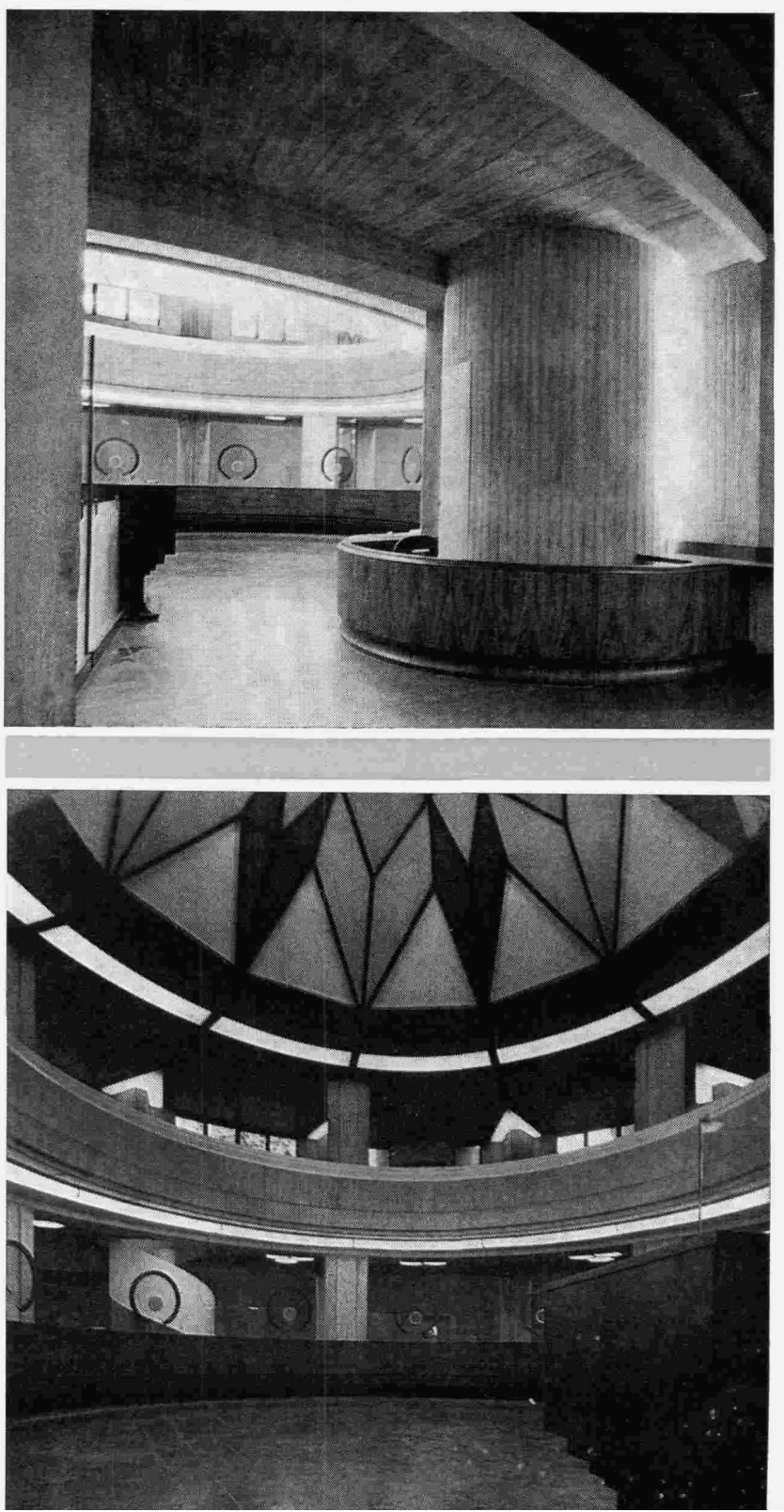
Tratándose el edificio de un ente arquitectónico de tipología mixta, situado en una zona residencial, su diseño se ha resuelto a base de una combinación de figuras geométricas que se integran entre sí para configurar la base del proyecto, en armonía con las exigencias funcionales.

El espacio arquitectónico así definido está constituido, a su vez, por una continua integración de los elementos dinámicos del interior con los del exterior, y viceversa, determinando una estructura interna en la cual está inserto el edificio. Desde él se disfruta de una bella vista panorámica sobre el mar, el castillo Malaspina, Apia, etc.

La estructura sustentante, bastante compleja, fue ejecutada en hormigón armado, a base de 12 pilastras que sostienen la plataforma «en corona circular» sobre la que gravitan las seis plantas dedicadas a alojamientos. Los cerramientos de los alzados exteriores fueron realizados con elementos prefabricados, formados por montantes y paneles ajustados entre sí y a la estructura sustentante; habiendo sido diseñado para que armonizaran con el ambiente circundante, habida cuenta asimismo la majestuosa presencia del palacio Malaspina, que se alza a corta distancia.

\section{ตำ}

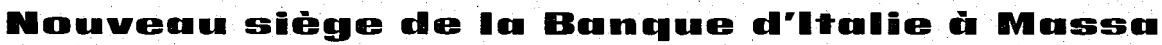

Prof. Giulio Roisecco, architecte

Le nouvel édifice est constitué par deux parties, clairement différenciées: celle occupée par les bureaux et services de la banque, situés au rez-de-chaussée et au sous-sol, et celle réservée aux logements destinés en partie aux employés, aux étages supérieurs.

La composition architecturale de cet édifice, avec un important volume cylindrique comme élément dominant, a donné un caractère nouveau à la Piazza Garibaldi, sur laquelle il a été bâti.

\section{Wew head office of the Bunk of Italy, at Massa}

Prof. Giulio Roisecco, architect

The new building will involve two parts which are clearly differentiated. One houses the administrative staff, and the other serves as a residence. The one occupied by the bank offices and other facilities is on the ground floor and semibasement; whilst the other containing the living quarters of the staff occupies the higher floors.

This building has a cylindrical part as its main architectural volume, and it adds character and forcefulness to the nearby Plaza Garibaldi.

\section{Meuer Sitz der Bank wom Italiem in Massa}

Por Giulio Roisecco, Architekt

Das neue Gebäude weist zwei klar voneinander unterscheidbare Teile auf, von welchen der eine für die Verwaltung, der andere für Wohnungen bestimmt ist. Die Verwaltungsräume sind im Erdgeschoss und im Souterrain untergebracht. Die Wohnungen, die zum Teil für die Angestellten bestimmt sind, liegen in den oberen Geschossen.

Die architektonische Komposition mit einem beherrschen zylindrischen Körper hat der Plaza Garibaldi, an der sie gelegen ist, einen neuen Charakter verliehen. 